\title{
Sudden Death in Patients with Chagas Disease
}

\author{
Edison Reis Lopes
}

Instituto de Ciências Biológicas e da Saúde, Universidade de Uberaba, Av. Nenê Sabino 1801, 38055-500

Uberaba, MG, Brasil

Key words: Chagas disease - sudden death

In 1922, Chagas and Villela affirmed that they knew of no other pathology which caused sudden death (SD) in such a high percentage as Chagas disease (CD). Later studies confirmed this statement and Bogliolo, a important researcher into the tropical pathology seen in Brazil this century, affirmed (in a pers. commun. 1978) that in percentage terms chagasic cardiopathy is responsible for more SD than ischemic cardiopathy.

The SD in CD, in practically all cases, is cardiac (Rocha 1986) and as in other cardiopathies (Paulo \& Schatz 1971) it is useful to distinguish between two types: expected (SED) and unexpected (SUD).

Two important aspects should be highlighted. Firstly, emphasize that the division between SED and SUD, contributes to the study of SD in individuals with Chagas disease, facilitating the observation of risk factors and the identification of those patients needing preventive care. The second aspect is of a medicolegal nature. For this branch of medical and legal practice, the unforeseeable aspect is a fundamental characteristic for diagnosing SD. Consequently the coroners do not include SED in the sudden deaths.

FREQUENCY, GENERAL CHARACTERISTICS AND IMPORTANCE OF SUDDEN EXPECTED AND UNEXPECTED DEATHS

Although many studies realized in Brazil and abroad refer to the high prevalence of SD in $C D$, few present numerical data, especially regarding SUD. Studies realized by the author during 1980, in an endemic area of American trypanosomiasis (Lopes \& Chapadeiro 1983) indicated that CD was responsible for $24.1 \%$ of the SUD in the city of Uberaba. A similar study carried out 10 years later (Lopes et al. 1995) showed that the frequency of this type of SD had fallen to $6.8 \%$. Data gathered in a field study (Macedo 1973) suggested that SUD occurs in approximately $37.5 \%$ of the chagasic

Fax: +55-34-318.5279.

Received 9 June 1999

Accepted 9 August 1999 patients which live in endemic areas. Prata (1959), analyzing hospitalized patients, observed that SED occurs in approximately $38 \%$ of uncompensated chronic chagasic patients. The analysis of these data combined with others confirms the findings of Dias (1985) and Prata et al. (1985) who showed that SD (including unexpected and expected) is the principal cause of death among those suffering from chronic chagasic cardiopathy.

SUD is the type of death which meets all the classical criteria of SD (Vibert 1903). In fact it "befalls more or less rapidly, in a few seconds, hours or even days, but in unpredictable manner, occurring without any apparent cause, in a hitherto healthy individual, or at least one who presented only slight disorders, or at least in appearances to those around him". As this type of SD occurs in patients without any apparent sign of clinical disease, it attracts attention and causes fear and constraint.

The majority of chagasics with SUD are male sex and aged on average 38 years. In $80 \%$ of the cases there is an associated family history.

It should be highlighted that the SUD of a chagasic does not imply that the patient was asymptomatic. We did a retrospective investigation (Prata et al. 1986) based on data obtained from family members and friends together with the circumstances of the deaths of 35 chagasics who died SED/SUD. This enabled us to verify that $35.2 \%$, while still alive, did not present any symptoms or suspicion of cardiopathy. This group comprises those chagasic patients which present SD as the first manifestation of the disease. In $57.1 \%$ of the cases, we managed to detect a history of dizziness (42.8\%), dyspnoea during physical activity (48\%), loss of consciousness $(34.2 \%)$ and palpitations (31.4\%). Dysphagia and constipation were present in 38\% of the cases. The death having been brought on by physical effort, emotion and rarely during sleep. In half of the cases, the lethal event was instantaneous and in the remainder it was preceded by premonitory symptoms. Regarding the electrocardiograms realized between one to five years before death, $95 \%$ of these cases showed abnormalities. 
SD in indetermined forms of CD (Rassi \& Rassi 1998) seem to be an exception. Rare cases have been reported of SUD in chagasic patients with a normal electrocardiogram before death (Porto 1974, Manzullo \& Darraidou 1983, Bestetti et al. 1993). However, in all, there are elements lacking for these to be characterized as an indetermined form. In addition, the patients of Porto and Manzullo et al., were not autopsied, which means it is impossible to definitively attribute responsibility for the SD to $\mathrm{CD}$.

From an anatomopathological point of view, in the cases of SUD, the hearts present essentially the same picture as those chagasic patients which die from SED or from nonsudden death. The differences are manifested especially in the shape, volume and weight of the organ and the aspect of the cavities and behavior of the lymph nodes situated between the aorta and the pulmonary (subepicardial lymph nodes). The shape is slightly elongated and the weight and volume show a slight increase [Heart weights ranged from 180 to $560 \mathrm{~g}$ (average $390 \mathrm{~g}$ ) in chagasics with SD. In chagasics who died in cardiac failure the heart weights ranged from 180 to $1030 \mathrm{~g}$ (average $544 \mathrm{~g}$ ) and in asymptomatic chagasics who had a violent death, the heart weights range from 240 to $450 \mathrm{~g}$ (average $310 \mathrm{~g}$ )]. The enlargement of subepicardial lymph nodes is more frequent and severe in chagasic patients with SUD than those which present other types of death. These macroscopic characteristics are of extreme importance and should be borne in mind by coroners and by forensic pathologists. Microscopically, the fundamental lesion is inflammatory and simultaneously compromises the epicardium, myocardium and parietal endocardium. From a qualitative point of view, the inflammatory process has similar characteristics to those observed in chagasic patients with cardiac insufficiency; quantitatively, however, the alterations are more suttle in the chagasics with SUD than those which present SED or nonsudden death.

The SUD of a chagasic individual is of great interest for the coroner as it is a suspicious type of death, in that its circumstances arouse doubts as to whether the cause was natural or violent. It frequently leads to problems with the police, labor law and others.

An electrophysiologic study in chronic chagasic patients (Scanavacca et al. 1994) included, among chagasic patients which might present with SED two distinct population: (1) chagasics with recurrent sustained tachycardia and which present SD in the evolution; (2) chagasics with congestive cardiac insufficiency who present SD as the sinal event. There is yet a third population: chagasics with SD as the first manifestation of the cardiopa- thy. In that last cases the SD is inexpected. According with Scanavacca et al., chagasic patients may benefit of electrophysiologic study after a critical clinical evaluation.

\section{THE MECHANISM OF SUDDEN DEATH IN} PATIENTS WITH CHAGAS' DISEASE

One of the most striking characteristics of both SUD and SED in CD is that the death occurs immediately, only a few minutes after onset of the symptoms.

As already mentioned in the beginning of this paper, SD in chagasics is classified, in almost all cases, as cardiac SD, with non-cardiac causes being an exception, such as for example encephalic vascular accident (Lopes et al. 1990). From the observations to date, it is known that it is almost always preceded by fibrillation which constitutes the terminal arrhythmia.

Among the factors which interact to cause the ventricular fibrillation, we highlight the anatomic substrate, the trigger elements and the facilitating factors. Foci of inflammation, areas of fibrose, ventricular dilation and vortex lesion favor the occurrence of reentry, which constitutes the principal electrophysiological mechanism involved in the chain of events leading to ventricular tachyarrhythmias in chronic chagasic cardiopathy. However, the presence of anatomic substrate alone is not capable of originating the tachyarrhythmia. The participation of trigger elements, in this case represented by the ventricular extrasystoles, is also usually necessary. Thus the propagation of these premature impulses through zones of unidirectional block and conduction disturbances, resulting from the myocardial structural alterations are capable of causing the reentry process. Completing the model of arrhythmic SD, is the role of the facilitating factors, which on interacting with the substrate and trigger elements may cause electrical instability in the system and cause fatal arrhythmias, such as ventricular fibrillation. The acute hemodynamic deterioration, hypoxemia, acidosis, electrolytic disorders, lesions of the autonomous nervous system (intra and extracardiac) constitute examples of factors which can destabilize the arrhythmogenic substrate. Amongst these, the behavior of the autonomous nervous system merits special attention.

CARLOS CHAGAS AND SUDDEN DEATH IN PATIENTS WITH CHAGAS DISEASE

As occurred with nearly all aspects of the CD, the discoverer of trypanosomiasis cruzi had his attention drawn to the SD of the endemia.

In 1912, during a conference held in São Paulo, Chagas manifested himself thus: "In the regions where thanks to the disease the number of adult individuals with profound cardiac disorders is impres- 
sive, one being almost able to affirm that the totality of the inhabitants of houses infested by the barbeiros present morbid phenomena with regard to the central circulation organ. An immediate consequence of this fact is the great number of rapid deaths occasioned by the disease, it being really impressive, in the statistics of lethality, the number of people who suddenly die from cardiac syncope". Here, it seems to us that Carlos Chagas was making reference to those cases we now consider as SED.

In 1916, Chagas made observations regarding cases of SUD. In a paper published in the Memórias do Instituto Oswaldo Cruz, he related: "Of great frequency are also the sudden deaths in the cardiac forms of the disease. This very fact constitutes one of the most curious notes in the clinical history of this trypanosomiasis, the lethality of which and number of deaths is really surprising. It being rare for families living in infested zones not to report the loss of one or more of its members in this way. Sometimes they die while still young, in full activity and with an apparently satisfactory state of health.

We have heard from sources worthy of trust, manifested surprise by the frequency of these SD, verified in middle-aged individuals, in full working conditions; and in our hospital service, we possess observations of some patients whose demise was from an almost instantaneous death. These, moreover, presented accentuated cardiac syndrome".

By 1916, Chagas had already published considerations regarding the mechanism of SD in $\mathrm{CD}$ : "What is the immediate cause of the sudden death? Is it the acute dilatation of the right ventricle by exhaustion of the tone of the heart muscle or stopping of the organ in diastole by the loss of that function? Is it a syncope of reflex nature dependent upon the conditions of the myocardium, or rupture of the muscle, as in one observation we made"?. In this same article cited one of the rare mechanisms of SED in CD: rupture of the right ventricle. To date, only two other cases of this pathology have been reported (Tostes Jr et al. 1990).

Finally, in 1922, Chagas and Villela published the article "Cardiac form of American trypanosomiasis" at broach the SD in CD they refer: "sudden death is extremely frequent in the region of endemic trypanosomiasis". (...) "We must at once refer to Mac William's hypothesis which was formed the basis for our argument and in which SD in intensive disorders of rhythm would be explicable by fibrilation of the ventricle".

\section{REFERENCES}

Bestetti RB, Freitas OC, Muccillo G, Oliveira JSM 1993. Clinical and morphological characteristics associated with sudden cardiac death in patients with Chagas disease. Eur Heart J 14: 80-87.

Chagas C 1912. O mal de Chagas. Soc Med Cir São Paulo 3: 34-66.

Chagas C 1916. Processos patogênicos da tripanozomiase americana. Mem Inst Oswaldo Cruz 8: 5-35.

Chagas C, Villela, E 1922. Forma cardíaca da trypanosomiase americana. Mem Inst Oswaldo Cruz 14: 5-61.

Dias ICP 1985. História Natural, p. 99-113. In J Romeu Cançado \& M Chuster (eds), Cardiopatia Chagásica, Fundação Carlos Chagas, Belo Horizonte.

Lopes ER, Chapadeiro E 1983. Morte súbita em área endêmica da doença de Chagas. Rev Soc Bras Med Trop 16: 79-84.

Lopes ER, Araújo RC, Tostes Jr S, Chapadeiro E 1990. Mecanismos pouco comuns de morte súbita no chagásico crônico. Rev Soc Bras Med Trop 22: 4-8.

Lopes ER, Marçal MVL, Stade C, Asai RK, Araújo FRC, Rivas LG, Moraes RR, Dalalio VD, Resende AV, Jorge BH 1995. Estudo comparativo da freqüência da morte súbita inesperada por doença de Chagas em Uberaba, nos anos de 1980 e 1990. Ver Soc Bras Med Trop 28: 109-112.

Macedo V 1973. Influência da Exposição a Reinfecção na Evolução da Doença de Chagas, Thesis, Faculdade de Medicina, Universidade Federal do Rio de Janeiro.

Manzullo E, Darraidou 1983. Riesgo de muerte por cardiopatia chagásica crónica. VI Reunion Nacional de Investigadores de la Enfermedad de Chagas, Argentina.

Paulo O, Schatz M 1971. On sudden death. Editorial, Circulation 43: 7.

Porto CC 1974. A doença de Chagas do ponto de vista médico-trabalhista. Arq Brasil Cardiol 27: 85-91.

Prata A 1959. Prognóstico e complicações na doença de Chagas. Rev Goiana Med 5: 87-96.

Prata A, Lopes ER, Chapadeiro E 1985. Morte súbita, p.114-120. In J Romeu Cançado \& M Chuster (eds), Cardiopatia Chagásica, Fundação Carlos Chagas, Belo Horizonte.

Prata A, Lopes ER, Chapadeiro E 1986. Características da morte súbita tida como não esperada na doença de Chagas. Rev Soc Bras Med Trop 19: 9-12.

Rassi A, Rassi Jr A 1998. Forma indeterminada da doença de Chagas, p. 793-797. In CC Porto, Doenças do Coração. Prevenção e tratamento, GuanabaraKoogan, Rio de Janeiro.

Rocha A 1986. Alterações Morfológicas do Sistema Excito-condutor do Coração em Chagásicos Crônicos Falecidos Subitamente, Thesis, Faculdade de Medicina, Universidade Federal de Minas Gerais.

Scanavacca M, Sosa E 1994. Estudo eletrofisiológico na cardiopatia chagásica crônica. Rev Soc Cardiol Estado de São Paulo 4: 168-176.

Tostes Jr S, Lopes ER, Chapadeiro E 1990. Morte súbita por ruptura espontânea do ventrículo direito em mulher chagásica crônica. Rev Soc Bras Med Trop 23: 225-228.

Vibert C 1903. Precis de Medicine Legale, JB Balliere et Fils, Paris. 